\title{
Revisiting the optimal stationary public investment policy in endogenous growth economies
}

\author{
Gustavo A. Marrero* \\ Universidad de La Laguna and ICAE
}

November 2005

\begin{abstract}
:
One strand of the literature on endogenous growth concerns models in which public infrastructure affects the private production process. A puzzle in this literature is that observed public investment-to-output ratios for developed economies tend to fall short of theoretical model-based optimal ratios. We reexamine the optimal choice of public investment in a more general and plausible framework, which allows for a gradual transition between different steady states, a lower depreciation rate for public capital than for private capital, an elasticity of intertemporal substitution that differs from unity and the need to finance a non-trivial share of public services in output in each period. Given other fundamentals in the economy, we show that the optimal public investment-to-output ratio is smaller for low-growth economies, for economies populated by consumers with low preferences for substituting consumption intertemporally and when public capital is durable. Moreover, for a calibrated economy, we show that a combination of these factors solves the public investment puzzle.
\end{abstract}

Keywords: Public investment, Stationary policy, Endogenous growth JEL Classification: E13, E62, O41

\footnotetext{
*Correspondance to: Gustavo A. Marrero, Departamento de Análisis Económico, Facultad de Ciencias Económicas, Universidad de La Laguna, Campus de Guajara, Santa Cruz de Tenerife, Tenerife, Spain. gmarrero@ull.es
} 


\section{Introduction}

Early empirical work by Aschauer (1989) and Munnell (1990) identified the significant impact that public infrastructures have on economic growth. One strand of the literature on endogenous growth relating to models in which public investment affects the private production process has been, in part, motivated by this empirical finding. Barro's (1990) study represents an important breakthrough in characterizing the influence of public infrastructure on growth and welfare in an endogenous growth setting. Subsequent work by Futagami et al. (1993), Glomm and Ravikumar (1994), Cassou and Lasing (1998, 2004), Turnovsky (1997), Aschauer (2000) and Marrero and Novales (2005) are variations of Barro's research. In these studies, public revenues derive from proportional income taxes and the government decides the stable ratio of public investment to output.

Since 1960, the public sector has gradually become less important in the productive activity of most developed economies. While total public outlays have represented meaningful shares of GDP during the last four decades, public investment-to-output ratios have generally declined over the same period. ${ }^{1}$ Nevertheless, this ratio has remained relatively stable since the 1990s. By 2000, public investment represented $3.7 \%$ of total real GDP in the OECD and $3.1 \%$ in the US. For a standard calibration, these figures are well below the optimal public investment-to-output ratios predicted by most recent studies. This considerable difference between current policies and most model-based optimal predictions suggests a public investment puzzle in the context of this literature.

These differences support the thesis that the suboptimal public infrastructure policy over the last decades is to blame for the productivity slowdowns of the 1970s and 1980s (Aschauer, 1989, and Munnell, 1990, among many others). However, in this context, by using a stylized one-sector endogenous growth model carefully calibrated for the post-war US economy, Cassou and Lansing (1998, 2004) and Marrero (2005) find that reduced public investment in the 1970s and 1980s accounted for only a small proportion of the productivity slowdown.

The goal of the paper is not to discuss the productivity slowdown, on which there is already an extensive literature. Rather, we revisit the optimal choice of public investment in a more general and plausible framework than those mentioned above. Our framework allows for i) long-lasting private and public capital stocks (Ai and Cassou, 1995, and Cassou and Lansing, 1998), ii) a lower depreciation rate for public capital than for private capital (Ai and Cassou, 1995), iii) an elasticity of intertemporal substitution below unity (as suggested by Prescott and others) and iv)

\footnotetext{
${ }^{1}$ See Cassou and Lansing (2004) and Marrero (2005) for a description of public investment downsizing in the OECD and the US, respectively. See also Kamps (2005).
} 
assumes that there is a need to finance a non-trivial proportion of public services in output in each period (Cassou and Lansing, 1998, and Marrero, 2005). This economy allows for a gradual transition between different steady states, which Futagami et al. (1993) found to be an important factor in determining optimal public investment policy in a Barro-type framework. Futagami et al. (1993) did not explicitly derive an expression for the optimal stationary public investment policy. In this paper, we contribute to filling this gap.

More concretely, the contribution of the paper is threefold. First, we obtain an implicit expression for the optimal stationary public investment-to-output ratio in a more general endogenous growth framework. ${ }^{2}$ Second, we assess the importance of i)-iv) factors for optimal stationary policy. Third, we reconsider the public investment puzzle based on a calibrated economy within our new framework.

A carefully examination of the implicit policy expression gives an important insight into the size and determinants of the optimal stationary public investment-to-output ratio. We show that the optimal ratio is less than the growth-maximizing ratio. Whereas the public capital elasticity and the subjective discount rate positively affect optimal public investment policy, as is well known (see, e.g., Barro, 1990, and Glomm and Ravikumar, 1994), the factors mentioned above have a negative effect on the optimal ratio, as we show. Moreover, the endogenous growth rate acts as an indirect channel through which the fundamentals of the economy may also affect the optimal policy. In the final section, for a carefully calibrated economy, we show that the model-based optimal public investment-to-output ratio falls between $3 \%$ and $4 \%$ for the benchmark and similar calibrations. A wider sensitivity analysis reveals that all the new factors in the economy must be taken into account simultaneously to obtain this result.

The rest of the paper is organized as follows. In Section 2, we show the public investment puzzle within the context of existing studies. In Section 3, we describe the economic model. In Section 4, we discuss the optimal stationary policy and carry out a numerical illustration. Section 5 concludes the paper.

\section{The public investment puzzle}

First, we summarize the optimal stationary public investment policy predicted by existing studies. Next, we point out the existence of a puzzle in this literature. Under a standard model-based calibration, we identify a significant difference between these theoretical optimal ratios and the empirically observed ratios in developed economies

\footnotetext{
${ }^{2}$ The condition we derive is similar to that derived by Turnovsky (2004) in a continuous-time non-scale growing economy with public and private capital, in which fiscal policy does not affect economic growth.
} 
by 2000 .

The pioneering work of Barro (1990) treats the flow of public infrastructure as an input into private production. The development of public infrastructure induces higher future returns to private investment, but also distorts private incentives to consume and save through higher taxes. Optimal policy equalizes the post-tax return of private capital and the return on public infrastructure. Barro obtained the wellknown result that the optimal share of output devoted to public investment equals the elasticity of public capital in the production function, $\theta .{ }^{3}$ Moreover, this optimal policy corresponds to the public investment ratio that maximizes growth.

In a similar dynamic framework, Glomm and Ravikumar (1994) assume that the stock of public infrastructure is input into private production. Since public capital is productive in subsequent periods, the optimal public investment-to-output ratio is $\beta \theta$, where $\beta$, which is between zero and unity, is the subjective discount rate of the representative household. ${ }^{4}$ In addition, if the government is constrained to finance a constant share of output devoted to public services, $\psi \in(0,1)$, in each period, the optimal public investment-to-output ratio is $\beta \theta(1-\psi)$, as in Marrero and Novales (2005). The negative effect of a positive $\psi$ on the net return to public capital makes the optimal ratio lower than those described above.

For developed countries, public investment-to-output ratios have generally declined since 1960, but have been reasonably stable during the last decade. By 2000, this ratio was about $3.7 \%$ for OECD countries and about $3.1 \%$ for the US economy.

\section{[INSERT TABLE 1 ABOUT HERE]}

For a standard calibration, Table 1 shows the optimal public investment-to-output ratios implied by above works. We assume that $\beta=0.97$ and $\psi=0.18$ (as in Cassou and Lansing, 1998). Since there is debate about the calibration of the public capital elasticity, we consider a range of values for this parameter. For small values of $\theta$, i.e., below 0.05 , the model-based optimal ratios are close to current public investment ratios for the OECD and the US. Although some empirical papers (e.g., Holtz-Eaking, 1994, Hulten and Schwab, 1991, and Tatom, 1991) obtain estimates of $\theta$ that are close to zero, a recent consensus has developed that suggests that this elasticity is between 0.1 and 0.2 (see, e.g., Ai and Cassou, 1995, Cassou and Lansing, 1998 and 2004, and Shioji, 2001). Hence, either current public investment policies are suboptimal or existing models omit relevant factors and hence offer misleading policy prescriptions.

\footnotetext{
${ }^{3}$ Aschauer (2000) obtains the same result in a similar framework.

${ }^{4}$ Glomm and Ravikumar (1994) consider the case in which public capital is not crowded out by private capital. Since private capital has a harmful effect on public capital under congestion (see also Barro and Sala-i-Martín, 1992), the optimal income tax rate and the optimal public investmentto-output ratio would be higher as a result.
} 
Related studies assume that public and private capital fully depreciate in one period, and the models reduce to the special case of an AK economy. Thus, they lack transitional dynamics. Moreover, to obtain analytical solutions, they assume a logarithmic utility function (i.e., that the elasticity of intertemporal substitution is unity).

Futagami et al. (1993) point out the importance of accounting for transitional dynamics on optimal policy design. Turnovsky (2004) emphasizes this issue in a non-scale economy that exhibits exogenous growth. In an economy with transitional dynamics, there is a trade-off between consumption during the transition and long-run growth, which causes the optimal public investment-to-output to be lower than the growth-maximizing ratio. Indeed, assuming a log-linear accumulation rule for public capital and a logarithmic utility function, Cassou and Lansing $(1998,2004)$ find the optimal stationary public investment-to-output ratio to be $\beta \theta \delta_{g} /\left[1-\beta\left(1-\delta_{g}\right)\right]$, where $\delta_{g}$ is the depreciation rate of public capital, which is between zero and unity. If public capital fully depreciates in one period, the economy lacks transitional dynamics and the optimal policy is as stated by Glomm and Ravikumar (1994). However, the smaller the depreciation rate, the slower are the transition dynamics and the more important is the welfare trade-off referred to above. Effectively, for $\delta_{g}<1$, the optimal ratio is always lower than $\beta \theta$. Nevertheless, for standard parameter values $\left(\delta_{g}=0.1\right)$, the optimal ratio remains well above $4 \%$ when the public capital elasticity exceeds 0.05 (see Table 1).

In subsequent sections, we revisit the optimal choice of public investment under a more general and plausible framework that allows for a gradual transition between different steady states, and reconsider the public investment puzzle based on a calibrated economy within our new framework..

\section{The economy}

We consider a general one-sector economy incorporating a continuum of identical firms, an infinitely lived household and a government. The model is similar to those of Cassou and Lansing (1998) and Marrero and Novales (2005), which incorporate durable capital and productive public expenditure. We also suppose that public capital depreciates at a slower rate than private capital, that the government is constrained to finance a constant share of output devoted to public services in each period, and that the elasticity of intertemporal substitution may differ from unity. The population growth rate is assumed to be zero and population size is normalized to unity. All variables are expressed in per capita terms. 


\subsection{Firms}

There is a single non-storable consumption good in the economy, $y$, which is produced with private capita stock, $k$, public capital, $g$, and labor, $l$. The household is the owner of the physical capital and firms. There exists an index of knowledge available to each firm, $z$, which augments the productive capacity of labor. ${ }^{5}$ The individual technology is described by the production function,

$$
f(k, \hat{l}, g)
$$

where $\hat{l}$ is effective labor, $\hat{l}=z l$, and $f(1,1,1)=A_{0}>0$ is a technological scale factor. We denote by $\alpha_{t}, \theta_{t}$ and $\phi_{t}$ the elasticities of output with respect to $k, g$ and $\hat{l}$, respectively, at time $t$. This specification is based on Ai and Cassou (1995) and Cassou and Lansing (1998).

Assumptions 1: The function $f(\cdot)$ is increasing, strictly concave, two times continuously differentiable, homogenous of degree one and satisfies Inada conditions. Inputs are complementary, thus cross-derivatives are positive. All factors are essential in the production process. The average capital stock across firms, $K$, is taken as a proxy for the knowledge index $z$ available to each single firm (Romer, 1986).

Remark 1: By the Euler's theorem, linear homogeneity of $f(\cdot)$ implies $\alpha_{t}+\theta_{t}+\phi_{t}=1$ for all $t$.

Because firms are identical, $K=k$ and per capita output is produced according to

$$
y=F(k, l, g)=f(k, k l, g) .
$$

We use $F(t)$ and $f(t)$ to denote $F\left(k_{t}, l_{t}, g_{t}\right)$ and $f\left(k_{t}, \hat{l}_{t}, g_{t}\right)$, respectively. We use $f_{k}(t), F_{k}(t)$ and $f_{k k}(t), F_{k k}(t)$ to denote the first and second time derivatives of $f(\cdot)$ and $F(\cdot)$, respectively, with respect to $k$ and so on of the indicated object, evaluated at a particular allocation.

Remark 2: $\quad F(t)=f(t)$ and $f_{g}(t)=F_{g}(t)=\theta_{t} F(t) / g_{t}$ for a particular allocation. However, since each firm neglects its own contribution on the aggregate capital stock, $F_{k}(t)$ and $f_{k}(t)$ are not equal. More precisely, $f_{k}(t)=\alpha_{t} F(t) / k_{t}$ and $F_{k}(t)=\left(\alpha_{t}+\phi_{t}\right) F(t) / k_{t}$.

\footnotetext{
${ }^{5}$ Specifying the public capital stock in per capita terms ensures that there are no scale effects associated with the number of firms. This specification can be viewed as incorporating a specific congestion effect related to total population (Barro and Sala-i-Martín, 1992).
} 


\subsubsection{The firm's problem [P1]}

Since investment decisions are made by households, the firm's problem is static. Firms demand $k$ and $l$, while $g$ and $K$ are taken as exogenous variables. Each firm pays the competitive-determined wage $w$ on the labor it hires and the rate $r$ on the capital it rents. Taking $g$ and $K$ as given, optimally leads to the usual marginal productivity conditions and the resultant firm profits, $\pi$, every period:

$$
\begin{aligned}
r_{t} & =f_{k}(t)=\alpha_{t} \frac{F(t)}{k_{t}}, \\
w_{t} & =f_{l}(t)=\phi_{t} \frac{F(t)}{l_{t}}, \\
\pi_{t} & =\left(1-\alpha_{t}-\phi_{t}\right) F(t)=\theta_{t} F(t) .
\end{aligned}
$$

\subsection{Households}

The single commodity good is valued by the household according to

$$
\sum_{t=0}^{\infty} \beta^{t} u\left(c_{t}\right)
$$

where $\beta$ is the discount factor, between zero and one, $c_{t}$ is per capita consumption of the representative household at time $t$ and $u: \mathbb{R}_{+} \rightarrow \mathbb{R}$ is the momentary utility function. The household is endowed with one unit of time. Since the household does not value leisure, this unit is supplied inelastically every period.

We use $u(t)$ to denote $u\left(c_{t}\right)$, and $u_{c}(t)$ and $u_{c c}(t)$ to denote the first and second derivative at time-t of $u(t)$ with respect to $c$. We will make use of the following functions: $\sigma(t)=-u_{c}(t) / c_{t} u_{c c}(t)$, which is the elasticity of intertemporal substitution at period $t$, and $\tilde{u}_{c}(t+1)=u_{c}(t) / u_{c}(t+1)$, which denotes the marginal rate of substitution between next-period and current consumption. It is worth noting that both measures are inversely related.

Assumptions 2: The function $u(\cdot)$ is increasing, strictly concave, two times continuously differentiable and satisfies Inada conditions.

The budget constraint faced by the household is

$$
c_{t}+k_{t+1} \leq w_{t} l_{t}\left(1-\tau_{t}\right)+k_{t}\left[1-\delta+r_{t}\left(1-\tau_{t}\right)\right]+\pi_{t}\left(1-\tau_{t}\right),
$$

every period, $\delta$ is the linear depreciation rate of private capital and $\tau_{t}$ is a tax rate 
applied to total income, which is determined outside of her control. ${ }^{6}$

\subsubsection{The household's problem [P2]}

The representative household maximizes (6) subject to (7), $c_{t}>0$ and $k_{t+1}>0$ and the transversality condition

$$
\lim _{t \rightarrow \infty} \beta^{t} k_{t+1} u_{c}(t)=0,
$$

that places a limit on the accumulation of private capital. The standard optimal consumption-saving decision is given by

$$
\beta\left[1-\delta+r_{t+1}\left(1-\tau_{t+1}\right)\right]=\tilde{u}_{c}(t+1) .
$$

\subsection{Government}

The government claims a constant proportion, $\psi$, of output to fund public services, $c_{g t}$, in each period,

$$
c_{g t}=\psi y_{t},
$$

which is taken as given. This assumption ensures that $c_{g}$ continues to represent a significant and realistic share of economic output as the economy grows. ${ }^{7}$ Public services do not contribute to either production or consumer welfare. In addition, public investment, $i_{g}$, is also a proportion, $x_{t}$, of output,

$$
i_{g t}=x_{t} y_{t}
$$

We assume that issuing debt is not allowed and a proportional tax on total income is the only way to finance total public expenses,

$$
c_{g t}+i_{g t}=\tau_{t} y_{t} \Leftrightarrow \tau_{t}=\psi+x_{t} .
$$

The following laws of motion for private and public capital stocks complete the description of the economy:

$$
\begin{aligned}
k_{t+1} & =i_{t}+(1-\delta) k_{t}, \\
g_{t+1} & =i_{g t}+\left(1-\delta_{g}\right) g_{t},
\end{aligned}
$$

where $i$ is private investment, $\delta_{g}$ is the linear depreciation rate of public capital, which

\footnotetext{
${ }^{6}$ Since $f(\cdot)$ is homogenous of degree one, from (3)-(5), we have that $\tau_{t}\left(w_{t} l_{t}+k_{t} r_{t}+\pi_{t}\right)=\tau_{t} y_{t}$.

${ }^{7}$ Cassou and Lansing (1998), Marrero and Novales (2005) and Marrero (2005), among others.
} 
might be lower than that of private capital. ${ }^{8}$ Given that $\delta, \delta_{g}<1$, this specification allows for durable private capital and generates transitional dynamics.

\section{The optimal stationary policy}

A feasible policy is a trio of non-negative and bounded sequences, $\pi=\left\{\tau_{t}, x_{t}, \psi\right\}_{t=0}^{\infty}$, with $\tau_{t}=x_{t}+\psi \leq 1$ for all periods, $t$. A price system is a pair of non-negative and bounded sequences, $q=\left\{r_{t}, w_{t}\right\}_{t=0}^{\infty}$.

Definition 1 A vector of sequences $\left\{c_{t}, c_{g t}, k_{t+1}, g_{t+1}, i_{t}, i_{g t}, l_{t}, y_{t}, r_{t}, w_{t}\right\}_{t=0}^{\infty}$ constitutes a $\pi$-competitive equilibrium if, given a feasible policy $\pi$, a price system $q$ and initial conditions $\left.k_{0}, g_{0}>0: i\right)\left\{l_{t}, k_{t+1}\right\}_{t=0}^{\infty}$ solve the profit maximizing problem of the firms [P1]; ii) $\left\{c_{t}, l_{t}, k_{t+1}\right\}_{t=0}^{\infty}$ solve the household's problem [P2]; iii) the technology constraints (2), (13), (14) hold and iv) markets clear every period,

$$
\begin{aligned}
l_{t} & =1, \\
y_{t} & =c_{t}+c_{g t}+i_{t}+i_{g t} .
\end{aligned}
$$

Definition 2 A balanced growth path (BGP) is a competitive equilibrium path along which per capita endogenous variables either stay constant or grow at a constant rate.

The following set of assumptions, given that cumulative inputs exhibit constant returns to scale in the aggregate $\left(\alpha_{t}+\theta_{t}+\phi_{t}=1\right.$ from Remark 1), guarantees the existence of a BGP in our economic model. ${ }^{9}$ An overbar denotes variables on such an equilibrium path.

Assumptions 3: i) the policy is stationary, i.e., $\tau_{t}=\tau$ and $x_{t}=x$; ii) $\lim _{k \rightarrow \bar{k}} \alpha_{t}=\alpha$, $\lim _{k \rightarrow \bar{k}} \theta_{t}=\theta$ and $\lim _{k \rightarrow \bar{k}} \phi_{t}=\phi$; iii) $\lim _{k \rightarrow \bar{k}} \tilde{u}_{c}(t+1)=\bar{u}_{c}$, constant and positive; iv) the return of private and public capital must be invariable along the BGP, i.e., $\lim _{k \rightarrow \bar{k}} f_{k}(t)=\bar{r}$ and $\left.\lim _{k \rightarrow \bar{k}} F_{g}(t)=\bar{F}_{g} ; \mathrm{v}\right)$ the return of private capital must be high enough, i.e., $\bar{r}>\frac{1-\beta(1-\delta)}{(1-\tau) \beta}$.

Following Jones and Manuelli (1997), conditions (i)-(iv) of Assumptions 3 ensure a constant growth rate of per capita variables on the BGP. Moreover, standard

\footnotetext{
${ }^{8}$ Auerbach and Hines (1987) estimated a depreciation rate in US of 0.137 for equipment and one of 0.033 for structures. Since private capital includes a larger share of equipment than public capital, the estimated depreciation rate for private capital is expected to be larger. Ai and Cassou (1995) found support for this in the form of an estimated $\delta_{g}$ of just over half that of $\delta$.

${ }^{9}$ See, e.g., Barro (1990), Rebelo (1991) and Jones and Manuelli (1997) for a more detailed description of these conditions.
} 
arguments imply that the paths for $y, c, k, g, c_{g}$, which solve the $\pi$-competitive equilibrium all grow at the same constant rate, $\bar{\gamma}$. Finally, condition (v) guarantees that $\bar{\gamma}$ is positive. Although $\bar{\gamma}$ must be positive along the BGP, it cannot be sufficiently large to allow households to follow a chain-letter action; i.e., (8) must hold on the BGP.

Remark 3: Since $u(\cdot)$ is increasing and strictly concave (Assumptions 2), the condition that $\bar{\gamma}>0$ is equivalent to $\bar{u}_{c}>1$.

Remark 4: The transversality condition (8) implies that the sequence of positive elements, $\left\{\beta^{t} k_{t+1} u_{c}(t)\right\}_{t=0}^{\infty}$ must converge to zero. Hence, $\lim _{t \rightarrow \infty} \frac{\beta^{t} k_{t+1} u_{c}(t)}{\beta^{t-1} k_{t} u_{c}(t-1)}<1$, which is equivalent to

$$
1+\bar{\gamma}<\bar{u}_{c} / \beta
$$

which is a condition that must be satisfied on the BGP.

Remark 5: On the BGP, $\bar{u}_{c}=\lim _{k \rightarrow \bar{k}} u_{c}\left(c_{t}\right) / u_{c}\left(c_{t}(1+\bar{\gamma})\right)$. Since $u(\cdot)$ is strictly concave and $\bar{\gamma}>0, \bar{u}_{c}$ is directly related to $\bar{\gamma}$. Indeed, for the standard CES function, $u\left(c_{t}\right)=\left(c_{t}^{1-1 / \sigma}-1\right) /(1-1 / \sigma), \sigma>0$, we have that $\bar{u}_{c}=(1+\bar{\gamma})^{1 / \sigma}$. Moreover, $\bar{u}_{c}$ is inversely related to $\sigma$.

\subsection{The Ramsey problem}

There are many competitive equilibria and BGPs implied by different government policies. The following Ramsey problem chooses the $\pi$-competitive allocation that maximizes (6). The government is said to be benevolent because it sets fiscal policy to maximize the welfare of the representative consumer, given the competitive equilibrium conditions of the household and firms. The Lagrangian to this problem is as follows:

$\max _{\left\{c_{t}, k_{t+1}, g_{t+1}, \tau_{t}\right\}_{0}^{\infty}} \sum_{t=0}^{\infty} \beta^{t}\left\{\begin{array}{c}u(t)-\lambda_{1 t}\left[u_{c}(t)-\beta u_{c}(t+1)\left(1-\delta+f_{k}(t+1)\left(1-\tau_{t+1}\right)\right)\right]- \\ -\lambda_{2 t}\left[g_{t+1}-\left(\tau_{t}-\psi\right) F(t)-\left(1-\delta_{g}\right) g_{t}\right]- \\ -\lambda_{3 t}\left[c_{t}+k_{t+1}-(1-\delta) k_{t}-\left(1-\tau_{t}\right) F(t)\right]\end{array}\right\}$,

where the first constraint corresponds to the household's consumption-saving condition, the second represents the accumulation of public capital and the third is the global resource constraint of the economy.

This problem has the noteworthy feature that its solution is, in general, timeinconsistent. Nevertheless, several standard assumptions allow us to ignore the timeinconsistency problem. We could either assume that the government can credibly commit at time zero to future taxes, or we could restrict fiscal policy to be stationary. 
In either case, since we want to compare our solution with optimal stationary policies predicted by existing studies, we solve the Ramsey problem and focus on the optimal long-run, stationary public investment policy. Interior optimal conditions for this problem are shown in the Appendix.

Conditions (38)-(44) describe the optimal stationary policy on the BGP. Combining (38) and (41), the optimal stationary policy must satisfy the following condition:

$$
\beta\left[1+(1-\psi) \bar{F}_{g}-\delta_{g}\right]=\bar{u}_{c}
$$

The marginal rate of transformation between current output and available public capital - net of depreciation and discounted by the factor $\beta$ - must equalize the rate at which the household wishes to substitute current and future consumption. A high level of $\bar{u}_{c}$ means that the household places little value on future consumption relative to current consumption. Thus, given other economic fundamentals and the proportion $\psi$ of total resources used by the government to fund public consumption, the optimal public investment policy should hardly crowd out current consumption, in which case, the public investment-to-output ratio should be low. The productivity of public capital is high in this case and the left-hand side of (19) equals the right-hand side. Similar reasoning applies to economies with low levels of $\bar{u}_{c}$.

In addition, given the equation for public capital accumulation (43), we have

$$
\bar{F}_{g}=\theta \frac{\delta_{g}+\bar{\gamma}}{x}
$$

Substituting (20) into (19) reveals that the optimal stationary public policy, $x^{+}$and $\tau^{+}$, must be such that

$$
\begin{aligned}
x^{+} & =\beta \theta(1-\psi) \frac{\bar{\gamma}+\delta_{g}}{\bar{u}_{c}-\beta\left(1-\delta_{g}\right)}, \\
\tau^{+} & =x^{+}+\psi
\end{aligned}
$$

For (21)-(22) to be conditions for an interior optimal stationary policy, the associated $\bar{\gamma}$ must be positive and must satisfy the transversality condition, (17), i.e.,

$$
1<1+\bar{\gamma}<\bar{u}_{c} / \beta
$$

We focus on interior optimal policies. ${ }^{10}$ The following proposition summarizes this important result under these circumstances:

Proposition 3 Given Assumptions 1, 2 and 3, and considering interior solutions,

\footnotetext{
${ }^{10}$ Numerically, we check that whether the solution to (21) violates the feasibility conditions only for unrealistic parameterizations.
} 
there exists a unique and positive stationary public investment-to-output ratio that solves (21) on the BGP.

Proof. Assumptions 1 and 2 ensure the existence and uniqueness of a solution to the competitive equilibrium for any given feasible policy. Following a standard argument, this result derives from the theorem of the maximum, since the choice set is compact and the objective function is strictly concave and continuous. Assumptions 3 guarantees that the BGP has a constant and positive steady-state growth rate. Solving for the BGP equilibrium given the level of $x$ in (21) yields a unique optimal stationary policy. Moreover, since $\bar{u}_{c}>1, \bar{\gamma}>0$ and $\beta, \delta_{g}<1$, this $x$ is positive

In general, since $\bar{\gamma}$ and $\bar{u}_{c}$ depend on fundamentals and policy parameters in a non-trivial manner, an explicit expression for the optimal stationary policy cannot be obtained. ${ }^{11}$ The next two corollaries particularize condition (21) for specific environments. The unique environment in which an explicit expression for the optimal public investment ratio can be determined is described in the first corollary. The result in the second corollary is used to carry out the numerical exercise below.

Corollary 4 Assume that $u(t)$ is consistent with $\bar{u}_{c}=1+\bar{\gamma}$ (i.e., $u(t)=\log c_{t}$ and thus $\sigma=1)$. If $\delta_{g}=1$, the optimal public investment-to-output ratio is the standard $\beta \theta(1-\psi)$.

Corollary 5 Assume that $u(t)$ is the standard CES function, $\left(c_{t}^{1-1 / \sigma}-1\right) /(1-1 / \sigma)$, with $\sigma>0$, where $\sigma$ is constant for all periods t. The optimality condition (21) is then given by

$$
x^{+}=\beta \theta(1-\psi) \frac{\bar{\gamma}+\delta_{g}}{(1+\bar{\gamma})^{1 / \sigma}-\beta\left(1-\delta_{g}\right)} .
$$

Although, in general, we cannot obtain an explicit expression for $x^{+}$, several important results arise from a careful examination of (21). As a point of reference, we take the standard optimal ratio, $\beta \theta(1-\psi)$. From $(21)$, it is easy to show that $x^{+}<(>) \beta \theta(1-\psi)$ whenever the following condition holds:

$$
1+\bar{\gamma}<(>) \bar{u}_{c}+\left(1-\delta_{g}\right)(1-\beta)
$$

Since $\bar{u}_{c}>1$ and $\beta, \delta_{g}<1$, it is worth noting that the right-hand side term in (23) is higher that the right-hand side expression in (25) for any feasible level of $\bar{u}_{c}, \beta, \delta_{g}$. Thus, in theory, $x^{+}$might be above or below the threshold $\beta \theta(1-\psi)$. The

\footnotetext{
${ }^{11}$ Although Futagami et al. (1993) pointed out that the optimal stationary public investment policy may differ substantially in an economy with transition dynamics, they did not specify the condition for this. Our condition (21) contributes in this respect.
} 
following proposition states this result in accordance with the relationship among the key variables $\bar{\gamma}, \bar{u}_{c}$ and $\delta_{g}$.

Proposition 6 Under Assumptions 1, 2 and 3, and considering interior solutions: i) if $\bar{u}_{c}>1+\bar{\gamma}$, the optimal public investment-to-output ratio, $x^{+}$, is lower than $\beta \theta(1-\psi)$ for any level of $\delta_{g}$; ii) if $\bar{u}_{c}=1+\bar{\gamma}$ and $\delta_{g}<1, x^{+}$is also below $\beta \theta(1-\psi)$; iii) if $\bar{u}_{c}=1+\bar{\gamma}$ and $\delta_{g}=1, x^{+}$is equal to $\beta \theta(1-\psi)$; iv) if $\bar{u}_{c}<1+\bar{\gamma}$ and $\delta_{g}=1$, $x^{+}$is higher than $\beta \theta(1-\psi)$; v) finally, if $\bar{u}_{c}<1+\bar{\gamma}$ and $\delta_{g}<1$, the condition (25) must be checked to determine whether $x^{+}$is greater than or less than $\beta \theta(1-\psi)$.

Although the optimal stationary public investment-to-output ratio may exceed $\beta \theta(1-\psi)$, it cannot do so by much. Indeed, the next proposition shows that the ratio cannot exceed $\theta(1-\psi)$. This threshold is the ratio that maximizes the steadystate growth rate in the related model of Marrero and Novales (2005), in which $\psi$ is positive.

Proposition 7 Under Assumptions 1, 2 and 3, and considering interior solutions, the optimal stationary public investment-to-output ratio is less than $\theta(1-\psi)$.

Proof. Rewrite the optimal public investment-to-output ratio as $\theta(1-g) \frac{\bar{\gamma}+\delta_{g}}{1 / \beta \bar{u}_{c}-\left(1-\delta_{g}\right)}$. The second term in this expression is less than unity, given (17) and, therefore, $x^{+}<\theta(1-g)$

In an economy in which consumers place little value on current consumption in terms of future consumption, a benevolent government sets a high level of $x^{+}$, generally above $\beta \theta(1-\psi)$ and close to the level that maximizes growth, $\theta(1-\psi)$. As a consequence, the resulting difference between economic growth and the marginal rate of substitution between future and current consumption would be large. However, the optimal public investment-to-output ratio does not exceed the ratio that maximizes growth, because under this policy there would be less consumption and growth on the BGP. On the other hand, the optimal public investment-to-output ratio would be well below $\beta \theta(1-\psi)$ and the resulting difference between $\bar{\gamma}$ and $\bar{u}_{c}$ would be small. In short, the optimal public investment-to-output ratio would be smaller for low-growth economies, economies populated by consumers with low preferences for substituting consumption intertemporally and with long-lasting public infrastructures.

\subsection{Direct and indirect effects on the optimal policy}

From (21), it is clear that the following fundamentals of the economy directly affect optimal public investment policy: $\beta, \theta, \psi, \delta_{g}$ and $\bar{u}_{c}$ - or $\sigma$ from Remark 5. While the effects on $x^{+}$of $\beta, \theta, \delta_{g}$ and $\sigma$ are positive, that of $\psi$ on $x^{+}$is negative. The 
intuition behind these relationships is straightforward. A lower discount factor, $\beta$, and a smaller marginal rate of substitution between present and future consumption means that households have a higher preference for current consumption relative to future consumption. On the other hand, a lower depreciation rate implies slower transition dynamics. Since $\beta<1$, the future (i.e., the long run) is less important than the short run for aggregate welfare under these circumstances. Lastly, $\theta$ is positively related to the rate of return on public capital, while a higher $\psi$ implies that a higher proportion of output must be financed by distortionary taxes, which reduces the return to private investment.

In addition, changes in these fundamentals might have indirect effects on the optimal policy through their effects on the endogenous growth rate. Indeed, the private capital depreciation rate can only affect the optimal policy through this channel. The total effect of all the other factors on the optimal policy is the sum of the direct

and indirect effects. For a calibrated economy, we evaluate these effects in the next section. We show that the strength of the indirect effects depends largely on the depreciation rate of public capital and on households' preferences between present and future consumption. For instance, if $1 / \bar{u}_{c}=1+\bar{\gamma}$, in which case, the elasticity of intertemporal substitution is unity, and if public capital fully depreciates in one period, the optimal public investment ratio is $\beta \theta(1-\psi)$, and there is no indirect effect.

\subsection{A numerical illustration}

We proceed next to look at numerical solutions for a calibrated economy that resembles some steady-state characteristics of the US postwar economy. We assume particular functional form of $u(\cdot)$ and $f(\cdot)$ and assign values to parameters in order to illustrate the relationship between the optimal stationary policy and the fundamentals of the economy.

We specify the per-period utility function of the CES class as

$$
u(c)=\frac{c^{1-1 / \sigma}}{1-1 / \sigma}, \sigma>0
$$

Meanwhile, the production function is a standard Cobb-Douglas function with public and private capital, a spillover factor and constant returns to scale in all factors productivity,

$$
\begin{aligned}
f(k, \hat{l}, g) & =A_{0} k^{\alpha}(z l)^{\phi} g^{\theta}, \\
F(k, l, g) & =A_{0} l^{\phi} k^{\alpha+\phi} g^{\theta}, \text { with } \alpha+\phi+\theta=1 .
\end{aligned}
$$


For these particular functions, the solution of the system (29), (30) and (24) gives the steady-state value of the public capital to private capital ratio, $\bar{g} / \bar{k}$, the economic growth rate $\bar{\gamma}$ and the optimal stationary policy $x^{+}$,

$$
\begin{aligned}
\beta^{\sigma}\left[1-\delta+(1-x-\psi) \alpha A_{0}(\bar{g} / \bar{k})^{\theta}\right]^{\sigma}-\left(1-\delta_{g}\right)-x A_{0}(\bar{g} / \bar{k})^{\theta-1} & =0 \\
\bar{\gamma}+\delta_{g}-x A_{0}(\bar{g} / \bar{k})^{\theta-1} & =0 .
\end{aligned}
$$

Condition (29) comes from combining (42) and (43), while (30) is the particularization to (43). From (29)-(30), it is easy to show that steady-state growth is maximized setting the standard $x=\theta(1-\psi)$.

\subsubsection{Values of the parameters}

The parametrization of the baseline economy is standard. The time unit is the natural year. Based on King et al. (1988) and many others, we choose $\phi=0.58$, the labor elasticity in the Cobb-Douglas technology. We use $\sigma=0.5$, as considered by Prescott and others. For depreciation rates, we take those levels estimated by $\mathrm{Ai}$ and Cassou (1995): $\delta=0.094$ and $\delta_{g}=0.038$. The value $\psi=0.18$ implies that the government spending on nonproductive goods and services is $18 \%$ of output, which is consistent with its post-war average. Since the elasticity of public capital is the most controversial parameter to assign an unquestionable value, a range of values will be examined. ${ }^{12}$ For the benchmark economy, however, $\theta$ is chosen together with $A_{0}$ and $\beta$ to match a steady-state per capita growth rate of $2.9 \%$, to reproduce a public to private capital ratio of 0.55 with $x=0.052$ and an after-tax interest rate of $6.9 \%,{ }^{13}$ which are consistent with their levels in the 60 s for the U.S. economy. Finally, recall that $\theta, \phi$ and $\alpha$ are not independent, since $\alpha+\theta+\phi=1$.

For our model economy, the baseline calibration sets the private investment-tooutput ratio to a little under $18 \%$, the share of output that is devoted to private consumption to be about $60 \%$ and total public receipts as a percentage of output

\footnotetext{
${ }^{12}$ For instance, Aschauer (1989) and Munnell (1990) estimate very high values of $\theta$, equal to 0.39 and 0.34, respectively. Lynde and Richmond (1992) and Ai and Cassou (1995) account for non-stationarity in the data and estimations are smaller but still significant: the former estimates $\theta=0.2$ using time series techniques, while the latter estimates $\varphi$ between 0.15 and 0.2 , using a GMM estimation process. In a more recent paper, Shioji (2001) uses dynamic pannel techniques and estimate the elasticity of output with respect to infrastructure to be somewhere around 0.1 and 0.15. On the other hand, papers by Holtz-Eaking (1994), Hulten and Schwab (1991) and Tatom (1991), among others, put that estimation very close to zero. Sturm et al. (1997) show a selective review of these empirical studies.

${ }^{13}$ See Cooley and Prescott (1995). Introducing privately issued real bonds into the consumer budget constraint, the optimally condition for bonds leads to $1+r^{*}=\exp (\gamma-\ln \beta)$. We calibrate $\beta$ by setting $r^{*}=0.069$ and $\gamma=0029$ in this expression.
} 
to be a little under $25 \%$. These ratios are common for the post-war U.S. and other develop economies.

We report the values of the parameters for the baseline economy in Table 1. Notice that $\theta=0.093$ - similar to that estimated by Shioji (2001) - and the resultant value of $\alpha$ is 0.327 , similar to the capital share used in the literature.

\section{[INSERT TABLE 2 ABOUT HERE]}

\subsubsection{Simulation results}

We first show the quantitative properties of the baseline economy. Then, we conduct a sensitivity analysis with respect to the following important parameters: the elasticity of public capital, $\theta$; the elasticity of intertemporal substitution, $\sigma$; the share of output devoted to public services, $\psi$; and the public and private capital depreciation rates, $\delta_{g}$ and $\delta$. The sensitivity analysis facilitates understanding of the determinants of the optimal stationary policy and of the level of the optimal investment-to-output ratio. In general, the numerical exercise helps solve the public investment puzzle described in Section 2.

For each parameterization, we solve the system (29), (30) and (24) numerically. We limit the sensitivity analysis to parameterizations that generate interior optimal policy solutions (i.e., condition (23) must be satisfied). Table 2 reports the optimal stationary public investment-to-output ratio under alternative parameterizations. The table is divided into blocks, one for each parameter. The first row of each block shows the optimal policy for the associated parameterization. The second row reports the public investment ratio that is consistent with a constant growth rate. They may differ each other because of the indirect effect.

\section{[INSERT TABLE 3 ABOUT HERE]}

The first column in the table reports the optimal stationary policy for the baseline economy. This implies that public investment must be $3.94 \%$ of real output. It is worth noting that the optimal ratio is between $3 \%$ and $4 \%$ for minor changes in all important parameters. For the baseline economy, the optimal ratio is substantially less than the standard $\beta \theta(1-\psi)=7.4 \%$. The associated growth rate is $2.8 \%$ and the marginal rate of substitution between future and current consumption is 1.057. Thus, for the baseline economy, $1+\bar{\gamma}$ is evidently lower than $\bar{u}_{c}$. All these results are consistent with Proposition 6.

Other important macro ratios under the optimal policy are: $c / y=61.1 \%, i_{k} / y=$ $17 \%$ and $g / k=43 \%$. With respect to the baseline economy, the public sector turns out to be less important for private production, and the public to private capital ratio has fallen from $55 \%$ to $43 \%$. On the other hand, private consumption and private 
investment represent a greater shares of output. These features are consistent with the macroeconomic trends in developed economies during recent decades (see Section 2).

For the baseline economy, it is worth noting that the optimal public investment-tooutput ratio is very similar to the average ratio in OECD countries and slightly above the ratio for the US, based on data for 2000 (see Table 1). Hence, economic elements may explain the public investment puzzle described in Section 2. Moreover, our results indicate that all elements combine to generate an optimal public investment-to-output ratio of between $3 \%$ and $4 \%$ under a realistic calibration.

The effect of $\beta$ and $\theta$ on the optimal policy is clearly positive from (24), as in existing studies. We focus on the new effects of $\delta_{g}, \sigma, \psi$ and $\delta$. The optimal ratio rises with the public capital depreciation rate. Moreover, $x^{+}$approaches $\beta \theta(1-\psi)$ and $\theta(1-\psi)$ if public capital fully depreciates in one period. In principle, a sufficiently low $\delta_{g}$ is needed to achieve a level of $x^{+}$below $4 \%$ for a reasonable calibration of the economy. However, this condition is not sufficient. In addition, the elasticity of intertemporal substitution must be less than unity. Indeed, using the benchmark level of $\delta_{g}$, the optimal ratio is 5.62 and just below $\theta(1-\psi)$ for $\sigma=1$ and $\sigma=1.625$, respectively. In addition, $\psi$ must be higher than about 0.15 for the optimal ratio being less than $4 \%$. For instance, if $\psi=0$, and all other parameters are unchanged, the optimal ratio is about $5 \%$.

The overall effects of $\delta_{g}$ and $\psi$ on the optimal policy are mainly direct effects, similarly to the effect of public capital elasticity. On the other hand, the indirect effect predominates in the overall effect of a change in $\sigma$, especially when $\sigma$ differs greatly from unity. The effect of $\delta$ is completely indirect.

In short, in our economic model, a public consumption-to-output ratio of above about 0.15, an elasticity of intertemporal substitution of less than unity, a public capital elasticity of below about 0.15 and a depreciation rate of capital of less than 0.125 are necessary for the optimal public investment-to-output ratio to be less than $4 \%$. Parameter values in these ranges are commonly used in studies of economic growth in developed economies.

\section{$5 \quad$ Final remarks}

We have revisited the optimal choice of public investment in a more general and plausible framework than those considered by most earlier papers in the endogenous growth literature. The following key elements are combined in a standard dynamic setting that incorporates public capital: (i) public and private capital are durable, which allows for a gradual transition between different steady states, (ii) public capital depreciates at a lower rate than private capital, (iii) the elasticity of intertemporal 
substitution is less than unity, (iv) a significant proportion of output is devoted to public services. Each of these factors were shown to play an important role in the optimal policy design proposed in earlier studies. In this context, a general condition for optimal public investment policy was derived. This condition depends on the endogenous growth rate and an explicit expression for the optimal policy is unobtainable. Nevertheless, careful examination of the implicit condition reveals important findings.

The optimal public investment-to-output ratio is less than the ratio that maximizes growth. We showed that the optimal public investment-to-output ratio is smaller for low-growth economies and for economies populated by consumers with low preferences for substituting consumption intertemporally. In general, given the fundamentals of the economy, a developed country with an initial high growth rate tends to stabilize its growth rate. Inflation and interest rates tend to fall and the financial sector becomes more competitive and efficient. Low interest rates and the development of flexible financial and credit markets tend to reduce the marginal rate to intertemporal substitution of consumption. Our findings suggest that this trend should be accompanied by an optimal strategy that reduces the share of output devoted to public investment. This pattern is consistent with recent trends in most developed economies.

The public capital elasticity and the discount factor in the utility function are two important determinants of the optimal policy, as earlier papers have already shown. The negative effect of the share of output devoted to public consumption is worth noting. Finally, the elasticity of intertemporal substitution and the public capital depreciation rate have positive and important effects on the optimal public investment-to-output ratio. In addition to affecting the optimal ratio directly, these parameters may also affect the optimal policy indirectly through the endogenous growth rate. This indirect channel is particularly important for measuring the overall effect of the elasticity of intertemporal substitution and the effect of the private capital depreciation rate. For other parameters, the total effect is dominated by the direct effect.

Finally, we used a calibrated economy to estimate the optimal public investmentto-output ratio and to resolve an existing puzzle in the public investment literature. This puzzle is that current public investment-to-output ratios of about $3 \%$ or $4 \%$ for developed economies are well below the optimal ratios predicted by most earlier theoretical models. For our calibrated economy, we showed that each of the model's elements contribute to generating optimal public investment-to-output ratios of less than $4 \%$. 


\section{References}

[1] Ai, C. and S.P. Cassou (1995). "A Normative Analysis of Public Capital", Applied Economics, 27, 1201-1209.

[2] Aschauer, D.A. (1989). "Is Public Expenditure Productive?", Journal of Monetary Economics, 23, 177-200.

[3] Aschauer, D.A. (2000). "Do States Optimize? Public Capital and Economic Growth", Annals of Regional Science 34 (3), 343-363.

[4] Auerbach, A.J. and J.R. Hines Jr. (1987). "Anticipated Tax Changes and the Timing of Investment", in The Effects of Taxation on Capital Accumulation, M. Feldstein (ed.), The University of Chicago Press, Chicago and London.

[5] Barro, R.J. (1990). "Government Spending in a Simple Model of Endogenous Growth", Journal of Political Economy, 98, 5, S103-S125.

[6] Barro, R.J. and X. Sala-i-Martín (1992). "Public Finance in Models of Economic Growth", Review of Economic Studies, 89, 645-661.

[7] Cassou, S.P. and K.J. Lansing (1998). "Optimal Fiscal Policy, Public Capital and the Productivity Slowdown", Journal of Economic Dynamics and Control, 22, 911-935.

[8] Cassou and Lansing (2004). "Fiscal Policy and Productivity Growth in the OECD", Canadian Journal of Economics, forthcoming.

[9] Cooley, T.F. and E.C. Prescott (1995). "Economic Growth and Business Cycle", in Cooley, T.F. (Ed.), Frontiers of Business Cycle Research. Princeton University Press, Princeton, NJ.

[10] Futagami, K., Y. Morita and A. Shibata (1993). "Dynamic Analysis of an Endogenous Growth Model with Public Capital", Scandinavian Journal of Economics, 95(4), 607-625.

[11] Glomm, G. and B. Ravikumar (1994). "Public Investment in Infrastructure in a Simple Growth Model", Journal of Economic Dynamic and Control, 18, 11731187.

[12] Glomm, G. and B. Ravikumar (1999). "Competitive Equilibrium and Public Investment Plans", Journal of Economic Dynamics and Control, 23, 1207-1224. 
[13] Holtz-Eakin, D. (1994). "Public-Sector Capital and the Productivity Puzzle", Review of Economics and Statistics, 76, 12-21.

[14] Hulten, C.R. and R.M. Schwab (1991). "Is There too Little Public Capital?", American Enterprise Institute Conference on Infrastructure Nedds.

[15] Jones, L.E. and R.E. Manuelli (1997). "The Source of Growth", Journal of Economic Dynamics and Control, 21, 75-114.

[16] Kamps, C. (2005). "New estimates of Government net Capital Stocks for 22 OECD Countries 1960-2001", IMF Staff Papers, forthcoming.

[17] King, R.G., Plosser, C.I., and S. Rebelo (1988). "Production, Growth and Business Cycles I: the Basic Neoclassical Model", Journal of Monetary Economics, 21, 195-232.

[18] Lynde, C. and J. Richmond (1992). "The Role of Public Capital in Production", Review of Economics and Statistics, 401-444.

[19] Marrero, G.A. (2005). "An Active Public Investment Rule and the Downsizing Experience in the US: 1960-2000", Topics in Macroeconomics, Vol. 5, no. 8.

[20] Marrero, G.A. and A. Novales (2005). "Growth and Welfare: Distorting versus Non-Distorting Taxes", Journal of Macroeconomics, in Press.

[21] Munnell, A. (1990). "How does Public Infrastructure Affect Regional Performance?", New England Economic Review, Sept./Oct., 11-32.

[22] Rebelo, S. (1991). "Long-run Policy Analysis and Long-run Growth", Journal of Political Economy, 99, 500-521.

[23] Romer, P.M. (1986). "Increasing Returns and Long-Run Growth", Journal of Monetary Economics, 94, 5, 1002-1037.

[24] Shioji, E. (2001). "Public Capital and Economic Growth: a Convergence Approach", Journal of Economic Growth 6, 205-227.

[25] Sturn, J.E., Kaper, G.H, and J. de Haan (1997). "Modelling Government Investment and Economic Growth on a Macro Level: a Review", In Brakman, S., Van Ees, H. and S.K. Kuipers (Eds.), Market Behavior and Macroeconomic Modeling. Macmillan/St. Martin's Press, London.

[26] Tatom, J.A. (1991). "Public Capital and Private Sector Performance", Federal Reserve Bank of St. Louis Review, 3-15. 
[27] Turnovsky, S.J. (1997). "Public and Private Capital in an Endogenously Growing Economy", Macroeconomic Dynamics 1 (3): 615-639.

[28] Turnovsky, S.J. (2004). "The Transitional Dynamics of Fiscal Policy: Long-run Capital Accumulation and Growth", Journal of Money, Credit and Banking, forthcoming. 


\subsection{Appendix: Optimal conditions}

The existence and uniqueness of a solution to the Ramsey problem is guaranteed by Assumptions 1 to 3 . This result derives from the theorem of the maximum, since the choice set in this problem is compact and the objective function is strictly concave and continuous. ${ }^{14}$

We define the following ratios: $\tilde{\lambda}_{3 t}=\lambda_{3 t} / u_{c}(t), \tilde{\lambda}_{2 t}=\lambda_{2 t} / u_{c}(t), \tilde{\lambda}_{1 t}=\lambda_{1 t} / k_{t+1}$ and $\tilde{u}_{c}(t)=u_{c}(t) / u_{c}(t+1)$. The elasticity of intertemporal substitution is denoted by $\sigma_{t}=-u_{c}(t) / c_{t} u_{c c}(t)$. We use that $l_{t}=1$ every period. Using these definitions, optimal conditions for $t>0$ of the Ramsey problem (18) are: ${ }^{15}$

$$
\begin{gathered}
\tau_{t}:-\alpha_{t} \tilde{\lambda}_{1 t-1}+\tilde{\lambda}_{2 t}-\tilde{\lambda}_{3 t}=0 \\
c_{t}: 1+\frac{1}{\sigma_{t}} \frac{\lambda_{1 t}}{c_{t}}-\tilde{\lambda}_{3 t}-\frac{1}{\sigma_{t}} \frac{\lambda_{1 t-1}}{c_{t}}\left[1-\delta+f_{k}(t)\left(1-\tau_{t}\right)\right]=0 \\
k_{t+1} \quad: \quad \beta \tilde{\lambda}_{1 t}\left(1-\tau_{t+1}\right) k_{t+1} \frac{\partial f_{k}(t+1)}{\partial k} \tilde{u}_{c}^{-1}(t+1)-\tilde{\lambda}_{3 t}+ \\
: \quad+\beta \tilde{\lambda}_{2 t+1}\left(\tau_{t+1}-\psi\right) F_{k}(t+1) \tilde{u}_{c}^{-1}(t+1)+ \\
: \quad+\beta \tilde{u}_{c}^{-1}(t+1) \tilde{\lambda}_{3 t+1}\left[(1-\delta)+\left(1-\tau_{t+1}\right) \tilde{u}_{c}^{-1}(t+1) F_{k}(t+1)\right]=0 \\
k_{g t+1}: \quad \beta \tilde{\lambda}_{1 t} \tilde{u}_{c}^{-1}(t+1)\left(1-\tau_{t+1}\right) k_{t+1} \frac{\partial f_{k}(t+1)}{\partial g}-\tilde{\lambda}_{2 t}+ \\
\quad+\beta \tilde{u}_{c}^{-1}(t+1) \tilde{\lambda}_{2 t+1}\left[\left(\tau_{t+1}-\psi\right) F_{g}(t+1)+\left(1-\delta_{g}\right)\right]+ \\
: \quad+\beta \tilde{u}_{c}^{-1}(t+1) \tilde{\lambda}_{3 t}\left(1-\tau_{t+1}\right) F_{g}(t+1)=0 \\
\lambda_{1 t}: u_{c}(t)-\beta u_{c}(t+1)\left(1-\delta+f_{k}(t+1)\left(1-\tau_{t+1}\right)\right)=0 \\
\lambda_{2 t}: g_{t+1}-\left(\tau_{t+1}-\psi\right) F(t)-\left(1-\delta_{g}\right) g_{t}=0 \\
\lambda_{3 t}: c_{t}+k_{t+1}-(1-\delta) k_{t}-\left(1-\tau_{t}\right) F(t)=0 .
\end{gathered}
$$

On the BGP, aggregate variables $y, c, k$ and $k_{g}$ grow at the constant rate $\bar{\gamma}$, while $\tilde{\lambda}_{1}, \tilde{\lambda}_{2}, \tilde{\lambda}_{3}, \tilde{u}_{c}, \sigma$ and the tax rate must be constant. We omit the subindex $t$ along such equilibrium path in what follows. Linear homogeneity of $f(\cdot)$ implies $\lim _{k \rightarrow \bar{k}} \frac{\partial f_{k}(\cdot)}{\partial g} k=\alpha \bar{F}_{g}$ and $\lim _{k \rightarrow \bar{k}} k \frac{\partial f_{k}(\cdot)}{\partial k}=\alpha \bar{F}_{k}-\bar{f}_{k}$. On the BGP, conditions (31)-(37)

\footnotetext{
${ }^{14}$ See Glomm and Ravikumar (1999) for a detailed discussion of existence and uniqueness in a similar framework.

${ }^{15}$ The time-inconsistency problem appears because the optimal condition of a time-variant tax rate might be different for $t=0$ than for $t>0$. We focus on stationary policies and on steady-state conditions, so we do not concern about this problem.
} 
reduces to:

$$
\begin{gathered}
\tau: \tilde{\lambda}_{2}-\tilde{\lambda}_{3}=\alpha \tilde{\lambda}_{1} \\
c: 1+\frac{1}{\sigma} \tilde{\lambda}_{1}(1+\bar{\gamma}) \frac{\bar{k}}{\bar{c}}-\tilde{\lambda}_{3}-\frac{1}{\sigma} \tilde{\lambda}_{1} \frac{\bar{k}}{\bar{c}}\left[1-\delta+\bar{f}_{k}(1-\tau)\right]=0 \\
k: \beta \tilde{\lambda}_{1} \bar{u}_{c}^{-1}(1-\tau)\left(\alpha \bar{F}_{k}-\bar{f}_{k}\right)-\tilde{\lambda}_{3}+\beta \tilde{\lambda}_{2}(\tau-\psi) \bar{u}_{c}^{-1} \bar{F}_{k}+ \\
: \quad+\beta \bar{u}_{c}^{-1} \tilde{\lambda}_{3}\left[(1-\delta)+(1-\tau) \bar{u}_{c}^{-1} \bar{F}_{k}\right]=0 \\
k_{g}: \quad \beta \tilde{\lambda}_{1} \bar{u}_{c}^{-1}(1-\tau) \alpha \bar{F}_{g}-\bar{\lambda}_{2}+\beta \bar{u}_{c}^{-1} \bar{\lambda}_{2}\left[(\tau-\psi) \bar{F}_{g}+1-\delta_{g}\right]+ \\
\quad+\beta \bar{u}_{c}^{-1} \bar{\lambda}_{3}(1-\tau) \bar{F}_{g}=0 ; \\
\lambda_{1}: 1-\beta \bar{u}_{c}^{-1}\left[1-\delta+\bar{f}_{k}(1-\tau)\right]=0 ; \\
\lambda_{2}: \bar{\gamma}+\delta_{g}-(\tau-\psi) \bar{F}_{g} / \theta=0 ; \\
\bar{c} \\
\lambda_{3}: \overline{\bar{k}}+\bar{\gamma}+\delta-(1-\tau) \bar{F}_{k} /(1-\theta)=0
\end{gathered}
$$




\section{TABLES:}

Table 1: Optimal stationary public investment-to-output ratio under alte rnative enviro num ents

\begin{tabular}{ccccc}
\hline $\begin{array}{c}\text { Public capital } \\
\text { elasticity }\end{array}$ & $\begin{array}{c}\text { Barro(1990), } \\
\text { Aschauer(2000) }\end{array}$ & $\begin{array}{c}\text { Glomm and } \\
\text { Ravikumar(1994) }\end{array}$ & $\begin{array}{c}\text { Marrero and Novales } \\
(2005)\end{array}$ & $\begin{array}{c}\text { Cas sou and Lansing } \\
(1998,2004)\end{array}$ \\
\hline \hline 0.05 & 0.050 & 0.049 & 0.040 & 0.038 \\
0.10 & 0.100 & 0.097 & 0.080 & 0.076 \\
0.15 & 0.150 & 0.146 & 0.119 & 0.115 \\
0.20 & 0.200 & 0.194 & 0.159 & 0.153 \\
0.25 & 0.250 & 0.243 & 0.199 & 0.191 \\
0.30 & 0.300 & 0.291 & 0.239 & 0.229 \\
\hline
\end{tabular}

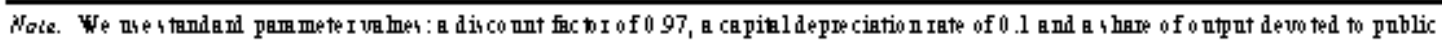

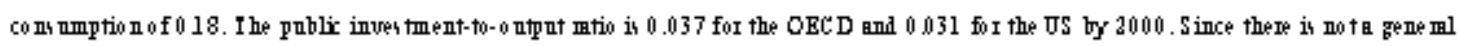
concent abo ut the level of the public capital elas tic ity in the prod ac tion func tion, we co nu ider a range of this im portant pammeter.

Table 2: The benchm ark calibration

\begin{tabular}{|c|c|c|c|c|c|c|c|c|c|}
\hline \multicolumn{10}{|c|}{ Parameters } \\
\hline$\beta$ & $\sigma$ & $\psi$ & $x$ & $A_{0}$ & $\alpha$ & $\phi$ & $\theta$ & $\delta$ & $\delta_{g}$ \\
\hline 0.965 & 0.500 & 0.180 & 0.052 & 0.779 & 0.327 & 0.580 & 0.093 & 0.094 & 0.038 \\
\hline \multicolumn{10}{|c|}{ Main steady-state and model-based ratios for the baseline economy } \\
\hline$\gamma$ & $c / y$ & $i_{k} / y$ & $i_{2} / y$ & $c_{2} / y$ & $g / k$ & $k / y$ & & & \\
\hline 0.029 & 0.603 & 0.167 & 0.052 & 0.18 & 0.55 & 1.36 & & & \\
\hline
\end{tabular}


Table 3: Optimal stationary public investment-to-output ratio. Sensitivity analysis

\begin{tabular}{|c|c|c|c|c|c|c|c|c|}
\hline & \multicolumn{8}{|c|}{ Blastic ity of public capital } \\
\hline & $0.097^{(2)}$ & 0.02 & 0.05 & 0.10 & 0.15 & 0.20 & 0.25 & 0.30 \\
\hline$x^{+}(\%)$ & 3.94 & 0.84 & 2.12 & 4.24 & 6.36 & 8.48 & 10.56 & 12.60 \\
\hline \multirow{3}{*}{ (1) } & 3.94 & 0.84 & 2.12 & 4.24 & 6.36 & 8.48 & 10.62 & 12.74 \\
\hline & \multicolumn{8}{|c|}{ Blastic ity of intertemporal substitution } \\
\hline & $0.500^{(2)}$ & 0.10 & 0.25 & 0.75 & 1.00 & 1.25 & 1.50 & $1.625^{(3)}$ \\
\hline$x^{+}(\%)$ & 3.94 & 2.56 & 3.08 & 4.80 & 5.62 & 6.44 & 7.24 & 7.62 \\
\hline \multirow{3}{*}{$(1)$} & 3.94 & 1.26 & 2.66 & 4.68 & 5.16 & 5.48 & 5.72 & 5.82 \\
\hline & \multicolumn{8}{|c|}{ Public consumption-to-output ratio } \\
\hline & $0.180^{(2)}$ & 0.00 & 0.05 & 0.10 & 0.15 & 0.25 & 0.30 & 0.35 \\
\hline$x^{+}(\%)$ & 3.94 & 4.70 & 4.50 & 4.28 & 4.08 & 3.66 & 3.44 & 3.02 \\
\hline \multirow[t]{3}{*}{ (1) } & 3.94 & 4.82 & 4.58 & 4.34 & 4.10 & 3.62 & 3.36 & 2.88 \\
\hline & \multicolumn{8}{|c|}{ Public capital depreciation rate } \\
\hline & $0.038^{(2)}$ & 0.00 & 0.10 & 0.15 & 0.25 & 0.50 & 0.75 & 1.00 \\
\hline$x^{+}(\%)$ & 3.94 & 2.50 & 5.22 & 5.80 & 6.42 & 7.02 & 7.22 & 7.34 \\
\hline \multirow[t]{3}{*}{ (1) } & 3.94 & 2.40 & 5.14 & 5.66 & 6.24 & 6.82 & 7.06 & 7.20 \\
\hline & \multicolumn{8}{|c|}{ Private capital depreciation rate } \\
\hline & $0.094^{(2)}$ & 0.000 & 0.025 & 0.051 & 0.100 & 0.125 & 0.150 & $0.165^{(4)}$ \\
\hline$x^{+}(\%)$ & 3.94 & 3.78 & 3.82 & 3.86 & 3.96 & 4.03 & 4.13 & 4.56 \\
\hline (1) & 3.94 & 3.94 & 3.94 & 3.94 & 3.94 & 3.94 & 3.94 & 3.94 \\
\hline
\end{tabular}

(1): The optimalratio keeping the growth rate unchenged. It difference with respect to the $\pi$ ahe in the aboue cohmn m easures the indirect effect caused by the param eter change trooughout the endogenous growth rate

(2): B enchm ark calibration and optim al policy under the base line econom $y$

(3): The policy satisfying the optimal interior condition breaks the NPG condition for $\sigma>1.625$

(4): The policy satisfying the optimal interior condition breaks that $\gamma>0$ for $\delta>0.165$ 